\begin{tabular}{|c|c|c|c|c|c|c|c|c|c|c|}
\hline & Plate No. & & Date & & $\underset{2410000+}{\text { J. D. }}$ & $\mathrm{V}_{1}$ & Red. & $\mathrm{V}_{2}$ & $(0-\mathrm{C}) \mathrm{V}_{1}$ & $(0-C) V_{2}$ \\
\hline 26 & $1145 \mathrm{C}$ & 1899 & Jan. & 27 & 4682.898 & -1.55 & & +85.6 & -0.06 & +1.9 \\
\hline 27 & $1151 \mathrm{D}$ & & & 29 & 4684.840 & +9.96 & & +46.3 & -2.47 & +2.1 \\
\hline 28 & $1154 \mathrm{D}$ & & & 30 & 4685.945 & +28.37 & & ......... & -9.68 & $\ldots \ldots$. \\
\hline 29 & $1159 \mathrm{D}$ & & Feb. & 6 & 4692.857 & +28.12 & & & +4.21 & $\ldots \ldots$ \\
\hline 30 & $1173 \mathrm{C}$ & & & 13 & 4699.790 & +26.80 & W & ......... & +4.07 & $\ldots \ldots$. \\
\hline 31 & $1176 \mathrm{~B}$ & & & 14 & 4700.918 & +50.08 & & -1.4 & +1.44 & -3.3 \\
\hline 32 & $1182 \mathrm{D}$ & & & 15 & 4701.922 & +67.06 & & -22.4 & -0.45 & -2.3 \\
\hline 33 & $1187 \mathrm{C}$ & & & 21 & 4707.831 & +12.90 & W & ......... & -0.03 & $\ldots . .$. \\
\hline 34 & $1205 \mathrm{~A}$ & & April & 3 & 4748.677 & +71.09 & $\mathrm{~W}$ & -21.9 & +2.26 & -0.2 \\
\hline 35 & $1219 \mathrm{C}$ & & & 10 & 4755.772 & -17.25 & W & +80.2 & -0.36 & +1.8 \\
\hline 36 & 1603D & 1900 & Jan. & 10 & 5030.915 & -22.24 & & +80.5 & -1.44 & -2.4 \\
\hline 37 & $1665 \mathrm{D}$ & & Feb. & 27 & 5078.881 & +69.58 & W & -18.7 & +1.89 & +1.6 \\
\hline 38 & $1700 \mathrm{~B}$ & & April & 4 & 5114.721 & -6.56 & $\mathrm{~W}$ & +64.9 & +0.14 & -1.6 \\
\hline 39 & $5156 \mathrm{~B}$ & 1908 & Mareh & 8 & 8009.761 & +82.66 & & -31.1 & +3.49 & +2.6 \\
\hline 40 & $5162 \mathrm{C}$ & & & 9 & 8010.827 & +62.82 & & -25.4 & -4.48 & -5.5 \\
\hline 47 & $5169 \mathrm{C}$ & & & 11 & 8012.817 & +26.43 & & .......... & +0.60 & $\ldots$ \\
\hline
\end{tabular}

TABLE II.

\begin{tabular}{|c|c|c|c|c|c|c|}
\hline & Plate No. & & Date & & & $\mathrm{v}_{1}$ \\
\hline (1) & 386 & 1905 & April & 14 & 6950.399 & +80.84 \\
\hline (2) & 390 & & & 19 & 6955.397 & +3.87 \\
\hline (3) & 643 & 1906 & April & 4 & 7305.385 & -26.91 \\
\hline (4) & 648 & & & 6 & 7307.378 & -18.33 \\
\hline (5) & 653 & & & 7 & 7308.366 & -3.20 \\
\hline (6) & 655 & & & 8 & 7309.360 & +25.25 \\
\hline (7) & 659 & & & 9 & 7310.355 & +44.55 \\
\hline (8) & 661 & & & 10 & 7311.316 & +65.47 \\
\hline (9) & 665 & & & 11 & 7312.362 & +77.04 \\
\hline (10) & 668 & & & 12 & 7313.368 & +82.09 \\
\hline (11) & 673 & & & 15 & 7316.350 & +39.07 \\
\hline (12) & 677 & & & 20 & 7321.335 & -24.22 \\
\hline
\end{tabular}

Lick OBServatory, 1908 April.

$\begin{array}{ccc}\mathrm{V}_{2} & (\mathrm{O}-\mathrm{C}) \mathrm{V}_{1} & (\mathrm{O}-\mathrm{C}) \mathrm{V}_{2} \\ -34.58 & +0.48 & +0.52 \\ +58.59 & -0.77 & +5.35 \\ +84.34 & -1.75 & -3.67 \\ +85.57 & -0.88 & +6.56 \\ +56.94 & -2.50 & -2.53 \\ +11.45 & +0.36 & +4.35 \\ -15.13 & +2.00 & +0.27 \\ -26.25 & -0.26 & +5.28 \\ -38.23 & +1.06 & -2.35 \\ +6.61 & +0.15 & -6.63 \\ +86.53 & -0.87 & +0.64\end{array}$

H. C. Plummer.

\title{
THE ORBIT OF $\beta$ HERCULIS.
}

The variability of the radial velocity of $\beta$ Herculis was discovered by Dr. Campbell in 1899 July and announced in the Astrophysical Journal, 11, 140, 1899. The spectrum of this star is indicated by $K$ in the Draper Catalogue and by XVa in Miss Maury's classification; that is to say, it resembles Arcturus in type.

A number of photographs of the spectrum sufficient for a determination of the orbit were made, chiefly in 1900 to 1902 . A discussion of these was undertaken by Dr. H. M. Reese, who, however, left the Lick Observatory in 1903 June before the results of his work had been put in shape for publication. It is on this work that the elements published in the "First Catalogue of Spectroscopic Binaries" (L. O. B., No. 79) are based. The date of periastron passage is there omitted, and it should be remarked that the position of the node and the projected mean distance as given are in error. The other elements are approximately correct.

It was at first intended to make a fresh discussion of the measured velocities and some preliminary work was done with this object. But a further inspection of the manuscript left by Dr. Reese made it evident that his work was so far advanced that to proceed further with a new investigation of the old material would involve a needless repetition of his computations. Indeed, a few corrections in the final stage and a certain amount of verification were all that was necessary to deduce a set of elements which well represent the orbit at the epoch of the observations.

After some trials the following elements were adopted by Dr. Reese to serve as a preliminary orbit:

ELEMENTS I.

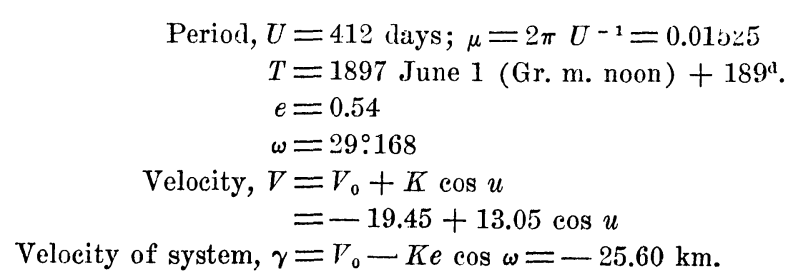


- The residuals computed from this set of elements given under $(\mathrm{O}-\mathrm{C})_{1}$ in the table at the end of this paper. With these and the system of weights 宛iven in the preceding column 32 equations of condi-

$$
\begin{array}{llll}
+15.120 u & -3.084 a & -9.330 w & -13.618 x \\
-3.084 & +22.529 & +6.725 & +44.088 \\
-9.330 & +6.725 & +48.359 & +15.900 \\
-13.618 & +44.088 & +15.900 & +120.912 \\
+15.560 & -58.487 & -24.937 & -146.939 \\
+4.060 & -9.671 & -0.345 & -18.156
\end{array}
$$

where $u=\delta K, v=10 \delta \omega, w=10 \delta e, x=10,000 \delta \mu$, $10 y=\delta T$, and $z=\delta V$. The solution by Dr. Reese gives the following set of corrections :

$$
\begin{aligned}
\delta \mu & =+0.0000534 \\
\delta T & =+2 .{ }^{1} 649 \\
\delta e & =+0.0098 \\
\delta \omega & =-0.079643 \text { cosec } 1^{\prime \prime}=-4.563 \\
\delta K & =-0.268 \mathrm{~km} . \\
\delta \gamma & =+0.080 \mathrm{~km} .
\end{aligned}
$$

the application of which to the previous set of elements gives the improved system:

\section{Elements II.}

$$
\begin{aligned}
\mu & =0.0153034 ; U=410.575 \text { days } \\
T & =\text { J. D. } 2415500.374=1901 \text { April } 25: 9^{\text {h }} \text { G. M. T. } \\
e & =0.5498 ; \phi=33^{\circ} 21^{\prime} \\
\omega & =24^{\circ} 36^{\prime} .3 \\
K & =12.782 \mathrm{~km} . ; V=-19.13+12.782 \cos u \\
\gamma & =-25.52 \mathrm{~km} .
\end{aligned}
$$

Hence may be deduced

$$
\begin{aligned}
a \sin i & =[4.13833] K U \cos \phi \\
& =60,280,000 \mathrm{~km} . \\
\text { and }\left(m+m^{\prime}\right) \sin { }^{3} i & =\mu^{2}(a \sin i)^{3}\left(1+m / m^{\prime}\right)^{3} \div[20.99508] \\
& =0.0519\left(1+m / m^{\prime}\right)^{3}
\end{aligned}
$$

where $m$ is the mass of the star whose spectrum has been observed and $m^{\prime}$ the mass of the other star, the Sun's mass being unity.

The residuals obtained by comparing the observed velocities with the values directly computed by means of Elements II are given in the column $(\mathrm{O}-\mathrm{C})_{2}$ in the table. The result of the least square solution is to reduce the sum $\left[p v^{2}\right]$ from 27.83 to 17.27 , and the latter number shows that the probable error of a single measure of unit weight is $\pm 0.52 \mathrm{~km}$.

Numbers corresponding to $(\mathrm{O}-\mathrm{C})_{2}$ have also been calculated by substituting the differential corrections found for the elements in the equations of condition. The excess of the numbers $(\mathrm{O}-\mathrm{C})_{2}$ calculated directly over those obtained by substitution are given tion were formed in the usual way according to the differential formulae of Lehmann-Filhés. The normal equations resulting are as follows:

$\begin{array}{lll}+15.560 y & +4.060 z & +5.336=0 \\ -58.487 & -9.671 & +9.175 \\ -24.937 & -0.345 & -3.730 \\ -146.939 & -18.156 & +5.707 \\ +194.977 & +22.276 & -14.924 \\ +22.276 & +29.250 & -5.097\end{array}$

in the last column of the table under the heading $\Delta$. The differences are due not only to possible accumulation of small errors in the course of the calculation but also to the linear form of the equations of condition, and their magnitude is fair evidence that no serious mistakes have been overlooked in the course of the computations and that the neglect of higher powers of the differential corrections has had no important effect on the final elements.

Two more recent plates have been measured and compared with the final set of elements. The results are given at the end of the table. With regard to the residuals derived from these plates it is to be remarked that a small systematic difference from the previous series is very possible since in the interval the Mills spectrograph has been reconstructed. The range of spectrum measured is therefore different, the center being shifted from $H \gamma$ to $\lambda 4500$, and this fact may well have a systematic effect in the case of a star which is not solar in type.

The first column of the following table gives a consecutive number to the plates and the second the number recorded by the observer. The date is given in the third column and the corresponding Julian Day in the fourth; the fraction is reckoned from Greenwich mean noon. The fifth column, headed "Red.," indicates by whom the plates have been measured and reduced: C stands for Dr. Campbell, W for Mr. Wright, Cs for Dr. H. D. Curtis, and R for Dr. Reese. The measured velocities are given under the heading "Vel.," and in the next column the weight assigned to each plate according to its quality in combining the equations of condition; where a plate has been measured by two persons, the mean of the two results has been adopted. Under $(0-\mathrm{C})_{1}$ stand the residuals calculated from Elements I and under $(\mathrm{O}-\mathrm{C})_{2}$ those calculated directly from Elements II. Finally the last column under $\Delta$ gives the excess of the quantities in the previous column over the corresponding quantities calculated by the substitution of the results of the least squares solution in the equations of condition. 


\begin{tabular}{|c|c|c|c|c|c|c|c|c|c|c|c|}
\hline 1 & $\begin{array}{c}\text { Plate No. } \\
765 \mathrm{~A}\end{array}$ & $1898^{\mathrm{D}}$ & $\begin{array}{l}\text { Date } \\
\text { June }\end{array}$ & 13 & $\begin{array}{l}\text { J. D. D. } \\
2410000+ \\
4454.768\end{array}$ & $\begin{array}{c}\text { Red. } \\
\text { W } \\
\mathrm{K}\end{array}$ & $\begin{array}{l}\text { Vel. } \\
-31.90 \\
-32.60\end{array}$ & $\begin{array}{c}\text { Wt. } \\
1\end{array}$ & $\begin{array}{l}(\mathrm{O}-\mathrm{C})_{1} \\
-0.86\end{array}$ & $\begin{array}{l}(\mathrm{O}-\mathrm{C})_{2} \\
-1.02\end{array}$ & $\begin{array}{c}\Delta \\
-0.04\end{array}$ \\
\hline 2 & $775 \mathrm{~A}$ & & & 19 & 4460.779 & W & -29.76 & 1 & +1.45 & +1.34 & -0.04 \\
\hline 3 & $1200 \mathrm{~B}$ & 1899 & Feb. & 27 & 4713.053 & $\mathrm{C}$ & -23.28 & 1 & +2.31 & +0.93 & 0.00 \\
\hline 4 & $1359 \mathrm{~A}$ & & July & 31 & 4867.767 & $W$ & -30.91 & 1 & +0.45 & +0.27 & -0.04 \\
\hline 5 & $1405 \mathrm{~A}$ & & Aug. & 21 & 4888.685 & C & -30.84 & 1 & -0.16 & -0.21 & -0.03 \\
\hline 6 & $1606 \mathrm{C}$ & 1900 & Jan. & 11 & 5031.080 & $\mathrm{C}$ & -20.95 & 1 & -2.27 & -1.27 & 0.00 \\
\hline 7 & $1642 \mathrm{~A}$ & & Feb. & 8 & 5059.033 & $\mathrm{R}$ & -12.71 & 1 & -1.07 & -0.11 & +0.05 \\
\hline 8 & $1667 \mathrm{~B}$ & & & 28 & 5079.045 & $\mathrm{R}$ & -6.67 & 1 & -0.17 & -0.03 & +0.07 \\
\hline 9 & $1678 \mathrm{~A}$ & & March & 12 & 5091.975 & $\mathrm{R}$ & -9.17 & 1 & -0.27 & -0.83 & +0.03 \\
\hline 10 & $1693 \mathrm{~A}$ & & & 26 & 5105.945 & $\mathrm{R}$ & -16.24 & 1 & +0.86 & +0.06 & +0.02 \\
\hline 11 & $1744 \mathrm{C}$ & & May & 22 & 5162.852 & $\mathrm{R}$ & -30.00 & 1 & +1.33 & +0.45 & 0.00 \\
\hline 12 & $1779 \mathrm{~A}$ & & June & 19 & 5190.724 & $\mathrm{R}$ & -31.51 & 1 & +0.84 & +0.11 & -0.01 \\
\hline 13 & $1849 \mathrm{~A}$ & & Aug. & 8 & 5240.702 & $\mathrm{R}$ & -32.46 & 1 & -0.23 & -0.60 & +0.05 \\
\hline 14 & $2074 \mathrm{C}$ & 1901 & April & 9 & 5484.008 & $\mathrm{R}$ & -7.68 & 1 & +0.10 & +0.23 & +0.02 \\
\hline 15 & $2128 \mathrm{E}$ & & May & 8 & 5513.840 & $\mathrm{R}$ & -15.40 & 1 & -0.82 & -0.70 & -0.01 \\
\hline 16 & $2147 \mathrm{E}$ & & & 19 & 5524.808 & $\mathrm{R}$ & -20.81 & 1 & +0.02 & -0.18 & -0.02 \\
\hline 17 & $2170 \mathrm{C}$ & & June & 17 & 5553.743 & $\mathrm{R}$ & -30.03 & $1 / 2$ & -0.83 & -1.57 & 0.00 \\
\hline 18 & $2215 \mathrm{C}$ & & Aug. & 6 & 5603.697 & $\begin{array}{l}\text { Cs } \\
\mathrm{R}\end{array}$ & $\begin{array}{l}-32.94 \\
-32.53\end{array}$ & 1 & -0.37 & -1.06 & 0.00 \\
\hline 19 & $2245 \mathrm{E}$ & & & 23 & 5620.705 & $\mathrm{R}$ & -30.90 & 1 & +1.60 & +0.98 & 0.00 \\
\hline 20 & $2261 \mathrm{C}$ & & Sept. & 3 & 5631.705 & $R$ & -32.75 & 1 & -0.28 & -0.84 & -0.01 \\
\hline$\stackrel{1}{21}$ & 22710 & & & 17 & 5645.693 & $\mathrm{R}$ & -32.30 & 1 & +0.04 & -0.45 & -0.01 \\
\hline 22 & $2328 F$ & & Dec. & 31 & 5750.111 & $\mathrm{R}$ & -29.64 & 1 & -0.57 & -0.50 & +0.07 \\
\hline 23 & $2340 \mathrm{E}$ & 1902 & Feb. & 13 & 5794.091 & $\mathrm{R}$ & -25.72 & 1 & +0.55 & +0.85 & -0.01 \\
\hline 24 & $2353 \mathrm{D}$ & & Mareh & 11 & 5820.972 & $\mathrm{R}$ & -23.43 & 1 & +0.30 & +0.72 & -0.01 \\
\hline 25 & $2365 \mathrm{~F}$ & & April & 9 & 5849.915 & $\mathrm{R}$ & -19.42 & $1 / 2$ & +0.28 & +0.74 & +0.01 \\
\hline 26 & $2368 \mathrm{C}$ & & & 13 & 5853.897 & $\mathrm{R}$ & -19.25 & $1 / 2$ & -0.28 & +0.16 & 0.00 \\
\hline 27 & $2404 \mathrm{~B}$ & & June & 8 & 5909.744 & $\mathrm{R}$ & -6.72 & 1 & +0.10 & +0.42 & +0.09 \\
\hline 28 & $2427 \mathrm{C}$ & & & 17 & 5918.912 & $\mathrm{R}$ & -10.22 & 1 & +0.18 & +1.14 & +0.03 \\
\hline 29 & $2463 \mathrm{~A}$ & & July & 20 & 5951.755 & $\mathrm{R}$ & -27.35 & $1 / 2$ & -0.99 & -1.23 & -0.05 \\
\hline 30 & $2482 \mathrm{~A}$ & & Aug. & 3 & 5965.753 & $\mathrm{R}$ & -26.27 & $1 / 4$ & +2.93 & +2.39 & -0.02 \\
\hline 31 & $2508 \mathrm{~B}$ & & & 19 & 5981.756 & $\mathrm{R}$ & -29.68 & 1 & +1.28 & +0.61 & 0.00 \\
\hline 32 & $2539 \mathrm{~B}$ & & Sept. & 14 & 6007.696 & $\mathrm{R}$ & -31.28 & 1 & +0.93 & +0.24 & 0.00 \\
\hline 33 & $4084 \mathrm{~A}$ & 1905 & Oet. & 24 & 7143.613 & & -6.42 & & ......... & +1.42 & .1...... \\
\hline 34 & $5148 \mathrm{~F}$ & 1908 & Feb. & 25 & 7997.074 & & -22.83 & & ........ & +1.20 & $\ldots \ldots .$. \\
\hline
\end{tabular}

H. C. Plummer.

Lick ObServatory, 1908 April.

\section{NOTE ON MR. NÖRLUND'S ORBIT OF $\xi$ URSAE MAJORIS.}

In his investigation of the orbit of the visual binary, $\xi$ Ursae Majoris, Mr. N. E. Nörlund has detected the existence of a perturbation in that system, having a period of 1.80 years. ${ }^{1}$ The principal component of this pair was found by me to be a spectroscopic binary, ${ }^{2}$ and it is of interest to note that a plat of all

1 Astr. Nach., 170, 123, 1905.

2 Astrophysical Journal, 12, 254, 1900. the observations of radial velocity so far secured at this observatory (to the number of seventeen) indicates a period very close to 1.8 years. The spectroscopic orbit will be more fully investigated here in the future.

W. H. WRIGHT.
Lick ObServatory, 1908 June. 